\title{
Mesoporous $\mathrm{TiO}_{2}$ Nanofiber as Highly Efficient Sulfur Host for Advanced Lithium- Sulfur Batteries
}

\author{
Xinyu Shan ${ }^{1}$, Zuoxing Guo ${ }^{1}$, Xu Zhang ${ }^{2}$, Jie Yang ${ }^{2}$ and Lianfeng Duan ${ }^{2}$ (D)
}

\begin{abstract}
Currently, lithium-sulfur batteries suffer from several critical limitations that hinder their practical application, such as the large volumetric expansion of electrode, poor conductivity and lower sulfur utilization. In this work, $\mathrm{TiO}_{2}$ nanofibers with mesoporous structure have been synthesized by electrospinning and heat treating. As the host material of cathode for Li-S battery, the as prepared samples with novelty structure could enhance the conductivity of cathode composite, promote the utilization of sulfur, and relieve volume expansion for improving the electrochemical property. The initial discharge capacity of $\mathrm{TiO}_{2} / \mathrm{S}$ composite cathode is $703 \mathrm{mAh} / \mathrm{g}$ and the capacity remained at $652 \mathrm{mAh} / \mathrm{g}$ after 200 cycles at 0.1 C, whose the capacity retention remains is at $92.7 \%$, demonstrating great prospect for application in high-performance Li-S batteries.
\end{abstract}

Keywords: $\mathrm{TiO}_{2}$ nanofibers, Mesoporous structure, Lithium-sulfur batteries, Cathode, Electrochemical property

\section{Introduction}

With the rapid development of portable equipment, handheld electronic products and hybrid electric vehicles, problems related to energy storage and conversion devices have attracted more and more attention. Because of low cost of sulfur, no harmful to the environment and higher theoretical energy density, lithium-sulfur batteries are being expected to become the most potential next generation of batteries in the world [1,2]. However, currently most traditional lithium-sulfur batteries suffer from several critical limitations that hinder their practical application on account of the large volumetric expansion of elemental sulfur during lithiation, poor conductivity of both the final products, and so on. In addition to this, in the discharge process, the major obstacle is that intermediate polysulfides are highly dissolved in organic electrolyte, which the so-called "shuttle effect" causes an irreversible loss of active sulfur, poor cycle stability and

\footnotetext{
*Correspondence: duanlf@ccut.edu.cn

${ }^{2}$ Advanced Institute of Materials Science \& Department of Materials Science and Engineering, Changchun University of Technology, Changchun 130012, China

Full list of author information is available at the end of the article
}

low coulombic efficiency during charge/discharge cycling [3-5].

To overcome these impediments for the development of $\mathrm{Li}-\mathrm{S}$ batteries, several strategies have been developed. For example, carbon acted as the sulfur matrix (graphene, carbon nanotubes and porous carbon [6-9], which mainly encapsulated the sulfur and polysulfide species into porous conductive materials through physical interaction. Meanwhile, more and more metal oxides as host materials for $\mathrm{Li}-\mathrm{S}$ batteries has been put forward, owing to their strong chemisorption effect towards polysulfides (LiPSs), including $\mathrm{SiO}_{2}, \mathrm{MnO}_{2}$, $\mathrm{TiO}_{\mathrm{x}}, \mathrm{Al}_{2} \mathrm{O}_{3}$, etc [10-14]. Among them, titanium dioxide $\left(\mathrm{TiO}_{2}\right)$ has drawn much attention due to its low cost, environmental protection and structural stability [15]. An et al. [16] prepared $\mathrm{TiO}_{2} @ \mathrm{NC}$ interlayer to absorpt polysulfide in $\mathrm{Li}-\mathrm{S}$ batteries. Because of good electronic conductivity, the reversible capacity reached $1460 \mathrm{mAh} / \mathrm{g}$ at $0.2 \mathrm{C}$. She et al. [17] designed a sulphur$\mathrm{TiO}_{2}$ yolk-shell nano-architecture to take in the large volumetric expansion of sulphur and minimize polysulphide dissolution, and the capacity decayed $0.033 \%$ every cycle after 1000 cycles. Li et al. [18] designed mesoporous hollow $\mathrm{TiO}_{2}$ spheres (HTSs) to solve the 
above problems, and the capacity retention of $71 \%$ at 1 $\mathrm{C}(1 \mathrm{C}=1672 \mathrm{~mA} / \mathrm{g})$. The mesoporous morphologies of host is important for the improving the electrochemical property of $\mathrm{Li}-\mathrm{S}$ batteries, because of the higher utilization of sulfur and chemisorption of lithium polysulfides. Moreover, it could afford large surface to infuse sulfur and accommodate volume changes during the charge/discharge reactions. Therefore, it is important to prepare the $\mathrm{TiO}_{2}$ with the mesoporous structure by simple methods and research on charge and discharge mechanism of Li-S batteries deeply.

Herein, the mesoporous $\mathrm{TiO}_{2}$ nanofibers were synthesized through an electrospinning method and subsequent thermal treatment. The mesoporous structure could encapsulate sulfur in their pores to trap soluble polysulfides $\left(\mathrm{S}_{8}\right.$ combining with the $\mathrm{Li}^{+}$in the anode), and accommodate large volumetric expansion of sulphur during lithiation/delithiation. In addition, the cathode conductivity is improved by $\mathrm{TiO}_{2} / \mathrm{S}$ composite as electrodes. It results in excellent electrochemical performance and significantly improved cycle stability of the $\mathrm{TiO}_{2} / \mathrm{S}$ composite cathode for $\mathrm{Li}-\mathrm{S}$ batteries.

\section{Experimental Section}

\subsection{Reparation of the Porous Nanofiber $\mathrm{TiO}_{2}$ Membranes}

The nanofiber $\mathrm{TiO}_{2}$ was prepared by electrospinning, the details as follows: 0.8 g Polyvinylpyrrolidone (PVP) was directly dissolved in $6 \mathrm{~mL}$ ethanol, and stirred for $3 \mathrm{~h}$. Meanwhile, to obtain a solution of $\mathrm{TiO}_{2}, 2.5 \mathrm{~mL}$ tetra-n-butyl titanate was dissolved in $2 \mathrm{~mL}$ acetic acid and $5 \mathrm{~mL}$ ethanol, and stirred for $3 \mathrm{~h}$. After that above mixture was mixed with the $\mathrm{PVP} /$ ethanol solution together, and stirring for $12 \mathrm{~h}$ at room temperature. This solution was loaded into a perfusion tube equipped with pipette tip through syringe with silvercoated needle. The pipette tip was connected to a highvoltage power supply. The electric voltage was set as $15 \mathrm{kV}$. Gained nonwoven fabrics was consist of PVP/ $\mathrm{TiO}_{2}$ nanofibers. After peeled off, nonwoven fabrics was calcined at $500{ }^{\circ} \mathrm{C}$ with heat-up speed of $5{ }^{\circ} \mathrm{C} / \mathrm{min}$ for $2 \mathrm{~h}$ in air flow, following by being calcined at $700{ }^{\circ} \mathrm{C}$ for $5 \mathrm{~h}$ to yield the final products.

\subsection{Preparation of $\mathrm{TiO}_{2} / \mathrm{S}$ Cathode}

As-prepared Nanofiber $\mathrm{TiO}_{2}$ and sulfur powder in a mass ratio of 3:7 were mixed and ground together for $30 \mathrm{~min}$. Then the mixture of powder was converted to a sealed stainless steel vessel and calcined for $24 \mathrm{~h}$ at $155{ }^{\circ} \mathrm{C}$. Finally, $\mathrm{TiO}_{2} / \mathrm{S}$ cathode was obtained, corresponding to a sulfur loading of $3.0 \mathrm{mg} / \mathrm{cm}^{2}$ and a sulfur content of 70 $\mathrm{wt} \%$ in the whole cathode.

\subsection{Materials Characterization}

The microstructure of the samples were investigated by X-ray diffraction (XRD, D-MAX II A X-ray diffractometer). The micro morphological images were obtained by field emission scanning electron microscope (FESEM, S4800, Hitachi) and transmission electron microscopy (TEM, Tecnai F20). Energy-dispersive X-ray spectroscope (EDS) was measured to gain the elemental mapping results. Thermogravimetric (TG) analysis (Perkin-Elmer TGA 7 thermogravimetric analyzer) was used to evaluate the sulfur content of $\mathrm{TiO}_{2} / \mathrm{S}$ cathode at a heating rate of $5{ }^{\circ} \mathrm{C} / \mathrm{min}$ from $40{ }^{\circ} \mathrm{C}$ to $600^{\circ} \mathrm{C}$ in flowing $\mathrm{N}_{2}$. The pore size distributions and specific surface area of $\mathrm{TiO}_{2} / \mathrm{S}$ cathode were measured by TriStar II 30203.02 (Micromeritics Instrument Corporation, USA).

\subsection{Electrochemical Performance Measurements}

CR2025 coin cells were prepared in a glove box, which is filled with argon and conducted electrochemical testings. The working cathode was fabricated by coating a mixture containing $10 \mathrm{wt} \%$ polyvinylidene fluoride (PVDF) as a binder dissolved in NMP, $10 \mathrm{wt} \%$ carbon black and $80 \mathrm{wt} \%$ active material (nanofiber $\mathrm{TiO}_{2} / \mathrm{S}$ ) on an aluminum foil following by drying at $60^{\circ} \mathrm{C}$ for $12 \mathrm{~h}$. Then the electrode disks were punched. Li metal was used as the anode. The electrolyte was a solution of 1.0 M LiTFSI dissolved in a mixture of dioxolane (DOL) $(99.8 \%$, SigmaAldrich) and 1,2-dimethoxyethane (DME) (99.5, SigmaAldrich) (1:1 by volume) with $\mathrm{LiNO}_{3}$ (1 wt\%) additive. Separator (Celgard 2400) was bought from Celgard Company. CR2025 coin cells were assembled in an argon filled glovebox with water and oxygen content kept below 0.1 ppm and used for electrochemical tests. Galvanostatic charge/discharge cycling was carried out using a LANDCT2001A instrument (Wuhan, China) in the voltage range 1.5 to $3 \mathrm{~V}$.

\section{Results and Discussion}

Figure 1 shows the fabrication and electrochemical process of $\mathrm{TiO}_{2} / \mathrm{S}$ composite as cathode for $\mathrm{Li}-\mathrm{S}$ battery. In step 1, the smooth of $\mathrm{TiO}_{2} / \mathrm{PVP}$ nanofibers was fabricated by electrospinning. Followed by pyrolysis of PVP, which is pyrolyzed into $\mathrm{CO}_{2}$ and $\mathrm{H}_{2} \mathrm{O}$ at high

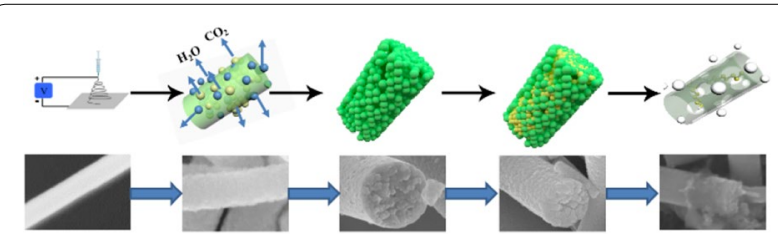

Figure 1 Schematic representation of the fabrication and cycle for $\mathrm{TiO}_{2} / \mathrm{S}$ composite cathode, and the following diagram is corresponding SEM 
temperature calcination in Air-flow, the $\mathrm{TiO}_{2}$ nanofibers with mesoporous structure could be gained. In step 4, the $\mathrm{TiO}_{2}$ infused with sulfur forming the $\mathrm{TiO}_{2} / \mathrm{S}$ cathode. The sulfur elements are uniformly distributed in the $\mathrm{TiO}_{2}$ nanofibers because of the mesoporous structure and polar metal-O bond. After testing for 200 cycles, clear and smooth surface of $\mathrm{TiO}_{2} / \mathrm{S}$ composite electrode can be observed from the typical SEM images (in step 5), which improving the electrochemical performance.

The SEM images of the synthesis $\mathrm{PVP} / \mathrm{TiO}_{2}$ composite nanofiber by electrospinning are shown in Figure 2. Figure 2(a) shows a typical low-magnification SEM image of $\mathrm{PVP} / \mathrm{TiO}_{2}$ composite fibers (the average diameter is about $200 \mathrm{~nm}$ ). The high-magnification SEM image of the composite nanofibers with smooth surface (Figure 2(b)). After electrospinning, the composite nanofibers were calcined to obtain pure $\mathrm{TiO}_{2}$ nanofibers. From the Figure 2(c) and (d), the $\mathrm{TiO}_{2}$ nanofibers with the average diameters about $200 \mathrm{~nm}$ were synthesized. Cross sections of enlarged $\mathrm{TiO}_{2}$ nanofibers in Figure 2(d) clearly shows that the fibers are very rough with many wormhole-like pores which could be used as good sulfur host to infuse high content of sulfur.

After preparing of $\mathrm{TiO}_{2} / \mathrm{S}$, the morphology of the $\mathrm{TiO}_{2}$ nanofibers as the host could not be changed after the infusion of sulfur (as shown in Figure 3(a) and (b)). The TEM images of $\mathrm{TiO}_{2}$ nanofibers before and after infusion of sulfur are shown in Figure 3(c), (d). The mesoporous structure can be clearly seen in the TEM image of $\mathrm{TiO}_{2}$ nanofibers, these porous structure was disappeared in the TEM image of $\mathrm{TiO}_{2} / \mathrm{S}$ nanofibers, reflecting the good infusion of sulfur by mesoporous structure in $\mathrm{TiO}_{2}$

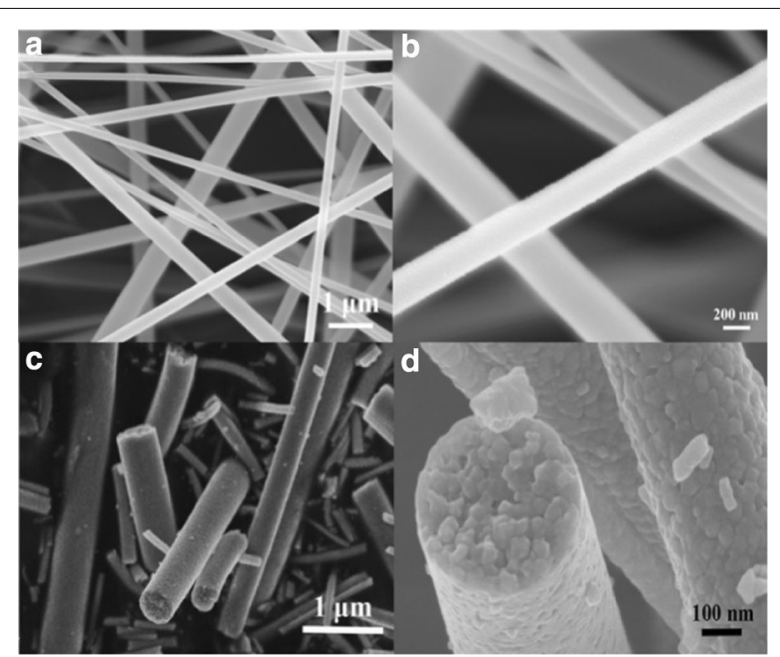

Figure 2 SEM images of the as-spun $\mathrm{PVP} / \mathrm{TiO}_{2}$ composite nanofibers: $\mathbf{a}$ the lower magnification and $\mathbf{b}$ the higher magnification, and after calcination the $\mathrm{TiO}_{2}$ nanofibers: $\boldsymbol{c}$ the lower magnification and $\mathbf{d}$ the higher magnification

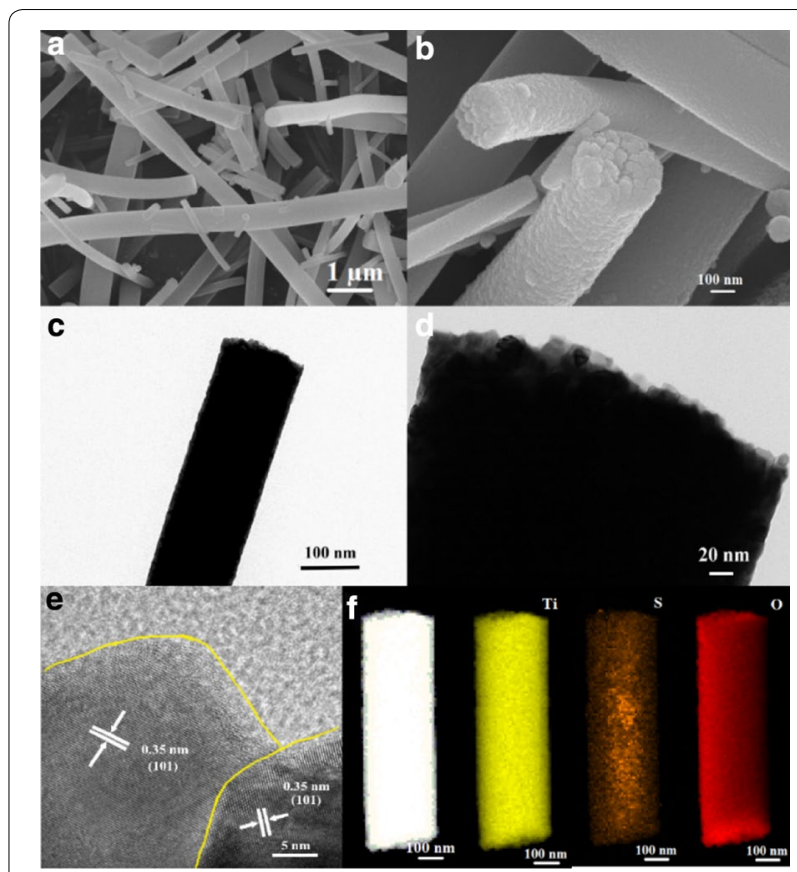

Figure $3 \mathrm{SEM}$ images of the $\mathrm{TiO}_{2} / \mathrm{S}$ composite nanofibers: a lower magnification, $\mathbf{b}$ higher magnification, c TEM images of the $\mathrm{TiO}_{2}$ nanofibers, $\mathbf{d}$ TEM images of the $\mathrm{TiO}_{2} / \mathrm{S}$ nanofibers, e HRTEM image of the $(\mathbf{c}), \mathbf{f}$ corresponding EDS mapping for elemental titanium, oxygen and sulfur

nanofibers. The HRTEM image (Figure 3(e)) reveals the clear lattice fringe spacing is $0.35 \mathrm{~nm}$, which is consistent with the (101) crystalline interplanar spacing of $\mathrm{TiO}_{2}$ structure. Additionally EDS area mapping showing in Figure 3(f), and can see the elemental of $\mathrm{Ti}, \mathrm{O}$, and $\mathrm{S}$ homogeneous distribution in all over the fiber.

The XRD patterns of $\mathrm{TiO}_{2}$ and $\mathrm{TiO}_{2} / \mathrm{S}$ nanofibers are shown in Figure 4 to confirm the crystal phase formation about synthesized $\mathrm{TiO}_{2}$ nanofibers and the existence of sulfur about $\mathrm{TiO}_{2} / \mathrm{S}$ nanofibers. The XRD pattern of $\mathrm{TiO}_{2}$ nanofibers demonstrates that $\mathrm{TiO}_{2}$ possesses almost pure rutile (JCPDS No. 65-0191) structure [19, 20]. Then, the XRD pattern of $\mathrm{TiO}_{2} / \mathrm{S}$ composites was well defined for orthorhombic structure of crystalline sulfur (JCPDS Card No. 08-0247), which is identical to the element sulfur powder [5, 21]. It reveals the $\mathrm{TiO}_{2}$ nanofibers with sulfur loading have been synthesized successfully.

The nitrogen adsorption and desorption isotherms of the $\mathrm{TiO}_{2}$ and $\mathrm{TiO}_{2} / \mathrm{S}$ composite were obtained, which correspond to type IV isotherms in the IUPAC classification with a typical mesopore hysteresis loop, from Figure 5(a) [22, 23]. Notably, compared with $\mathrm{TiO}_{2} / \mathrm{S}$ composite, $\mathrm{TiO}_{2}$ has larger pore volume and specific surface area. The pore size distribution of $\mathrm{TiO}_{2}$ fibers is in the range of 20-30 nm by Barrett-Joyner-Halenda as shown in Figure 5(a) inset. After sulfur incorporation, the fibers 


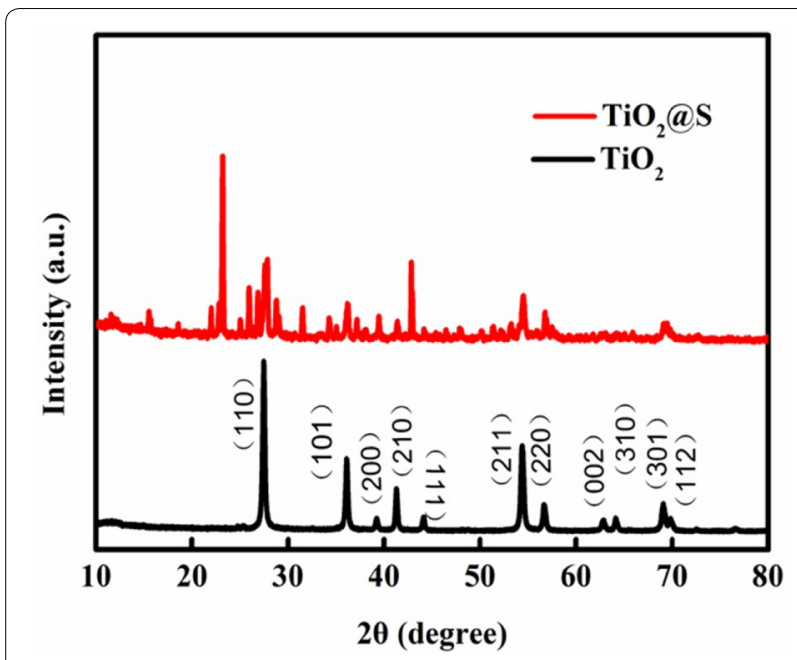

Figure 4 XRD patterns of as-spun electrospun $\mathrm{TiO}_{2}$ and $\mathrm{TiO}_{2} / \mathrm{S}$ nanofibers
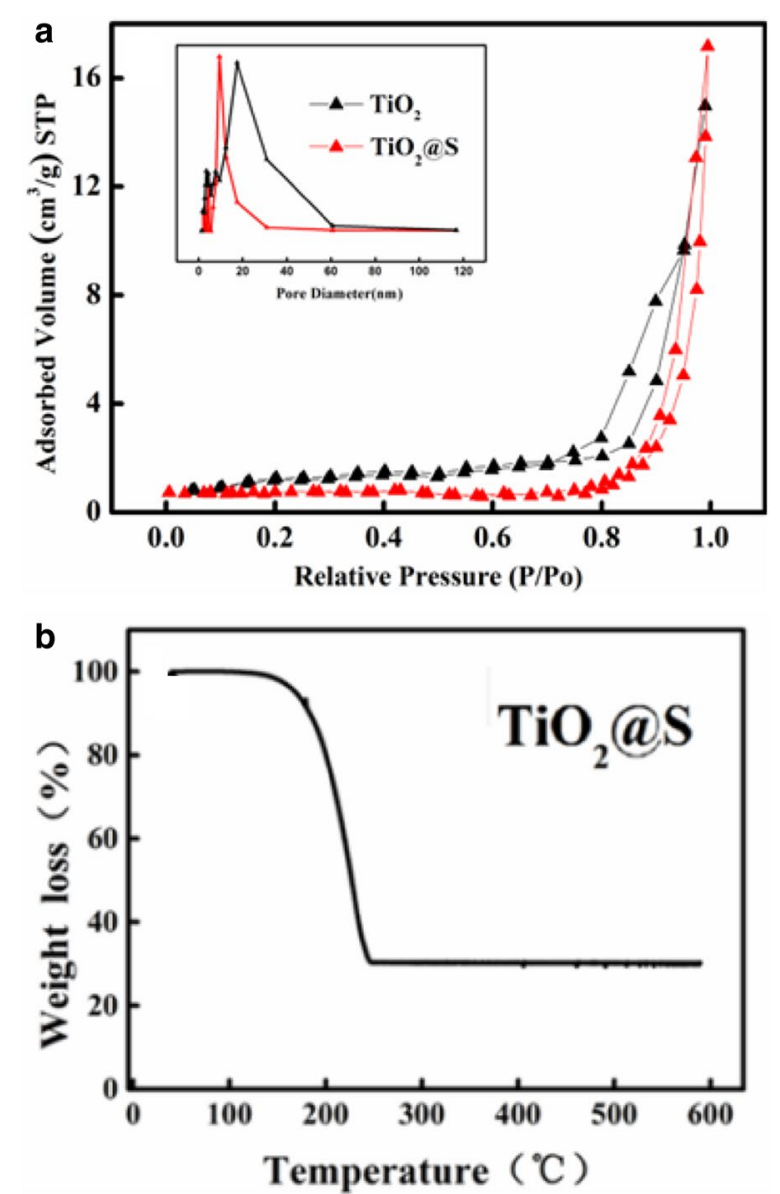

Figure 5 a Nitrogen adsorption-desorption isotherms and corresponding pore size (inset) distribution of $\mathrm{TiO}_{2}, \mathrm{TiO}_{2} / \mathrm{S}$ composite, b Thermogravimetric plot of $\mathrm{TiO}_{2} / \mathrm{S}$ composite in Ar atmosphere heating from room temperature to $600{ }^{\circ} \mathrm{C}$ pore distribution decrease to $10-20 \mathrm{~nm}$, because $\mathrm{S}$ particles is covered on or embedded into the mesopores of $\mathrm{TiO}_{2}$ fibers. To evaluate the content of sulfur in $\mathrm{TiO}_{2} / \mathrm{S}$ composite, thermo gravimetric (TGA) was performed from room temperature to $600{ }^{\circ} \mathrm{C}$ at a heating rate of $10{ }^{\circ} \mathrm{C} / \mathrm{min}$ under $\mathrm{N}_{2}$ atmosphere. The sulfur content in $\mathrm{TiO}_{2} / \mathrm{S}$ nanocomposite (Figure $5(\mathrm{~b})$ ) is estimated as high as $70 \mathrm{wt} \%$, which demonstrates such higher sulfur loading.

Figure 6(a) and (b) display the galvanostatic the discharging-charging curves of the $\mathrm{TiO}_{2} / \mathrm{S}$ composite electrode at a current rate of 0.2 and $0.5 \mathrm{C}(1 \mathrm{C}=1672 \mathrm{~mA} / \mathrm{g})$. The profile apparently shows the two plateaus in the discharging curves, which could be assigned to the two-step reaction of sulfur with lithium. The first plateau, at $2.35 \mathrm{~V}$, was due to the reduction of sulfur to higher polysulfide. The low voltage plateau, at $2.1 \mathrm{~V}$, showed the reactions of the higher polysulfides $\left(\operatorname{Li}_{2} \mathrm{~S}_{n}, 4 \leq n \leq 8\right)$ finally the further to the lower polysulfides $\left(\mathrm{Li}_{2} \mathrm{~S}_{n}, n \leq 3\right)$ [24-27]. And the initial discharge capacity and charge capacity of as prepared electrode were $763 \mathrm{mAh} / \mathrm{g}$ and $827 \mathrm{mAh} / \mathrm{g}$ at $0.2 \mathrm{C}$, respectively. And at $0.5 \mathrm{C}$ as shown in Figure 6(b), the electrode discharge capacities was found to be $423 \mathrm{mAh} / \mathrm{g}$, and charge capacities was $405 \mathrm{mAh} / \mathrm{g}$.

The excellently stable cycling performance of $\mathrm{TiO}_{2} / \mathrm{S}$ composite electrodes at different current densities have been shown in Figure 6(c). The $\mathrm{TiO}_{2} / \mathrm{S}$ electrodes exhibit the excellent capacity retention at $0.1,0.2$ and $0.5 \mathrm{C}$. The initial discharge capacity was $703 \mathrm{mAh} / \mathrm{g}$ and the capacity remained at $652 \mathrm{mAh} / \mathrm{g}$ after 200 cycles at $0.1 \mathrm{C}$. Figure $6(\mathrm{~d})$ is the discharge rate capability performance with 100 cycles at different current densities. When the current density is increased to $0.2,0.5$ and $1 \mathrm{C}$, the discharge
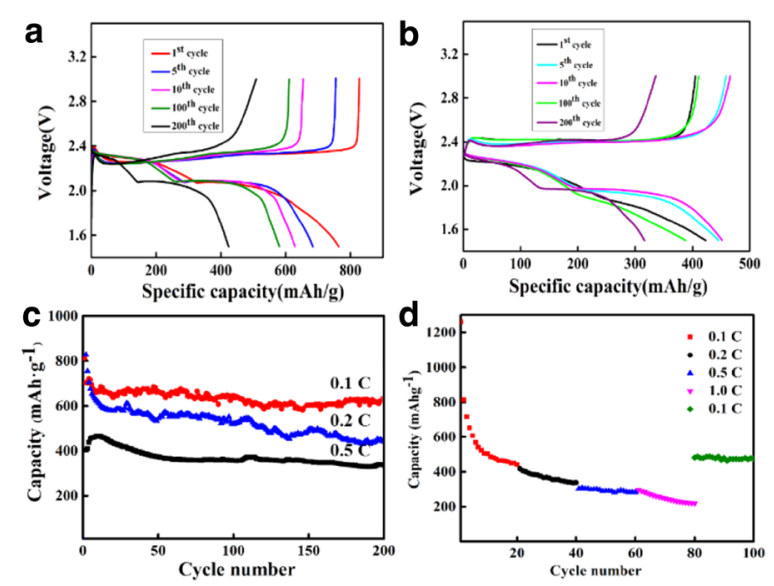

Figure 6 Electrochemical performance of $\mathrm{TiO}_{2} / \mathrm{S}$ nanocomposite structures. Galvanostatic charge-discharge voltage profiles of $\mathrm{TiO}_{2} / \mathrm{S}$ cathodes between 1.5 and $3.0 \mathrm{~V}$ at a $0.2 \mathrm{C}, \mathbf{b} 0.5 \mathrm{C}, \mathbf{c}$ Cycling performance of $\mathrm{TiO}_{2} / \mathrm{S}$ cathodes at a current density of $0.1 \mathrm{C}, 0.2 \mathrm{C}$ and $0.5 \mathrm{C}$, d Rate capability of $\mathrm{TiO}_{2} / \mathrm{S}$ composite electrodes at various current densities from $0.1,0.2,0.5$ to $1 \mathrm{C}$ 
capacities are 498, 402 and $298 \mathrm{mAh} / \mathrm{g}$. When the current density returns to $0.1 \mathrm{C}$, the reversible capacity was recovered to $613 \mathrm{mAh} / \mathrm{g}$, indicating the reliability and stability of the $\mathrm{TiO}_{2} / \mathrm{S}$ composite electrode.

The SEM images of the $\mathrm{TiO}_{2} / \mathrm{S}$ cathode after cycled 200 times are displayed in Figure $7(\mathrm{a})$. The $\mathrm{TiO}_{2} / \mathrm{S}$ fibers are still maintains the original fiber structure, although the some nanowire structure was destroyed. From Figure 7(b)-(d), the cathode elemental of $\mathrm{Ti}, \mathrm{O}$, and $\mathrm{S}$ still displays homogeneous distribution. It reveals that sulfur could be trapped in the nanofibers after 200 cycles, and further shows the advantages of mesoporous nanofibers in repeated cycling, which accordingly enhances the cyclic stability and rate capability. Figure $7(\mathrm{e})$ is corresponding reaction mechanism of the $\mathrm{TiO}_{2} / \mathrm{S}$ cathode during cycling. In the discharge process, $\mathrm{S}_{8}$ (elemental sulfur) in the nanofibers is combined with the $\mathrm{Li}^{+}$from the anode, and reduced to form soluble $\mathrm{Li}_{2} \mathrm{~S}_{n}(2 \leq n<8)$, which is also trapped in the mesoporous structure without diffused into the electrolyte and transferred to anode [28]. Then the soluble $\mathrm{Li}_{2} \mathrm{~S}_{n}$ is further reduced

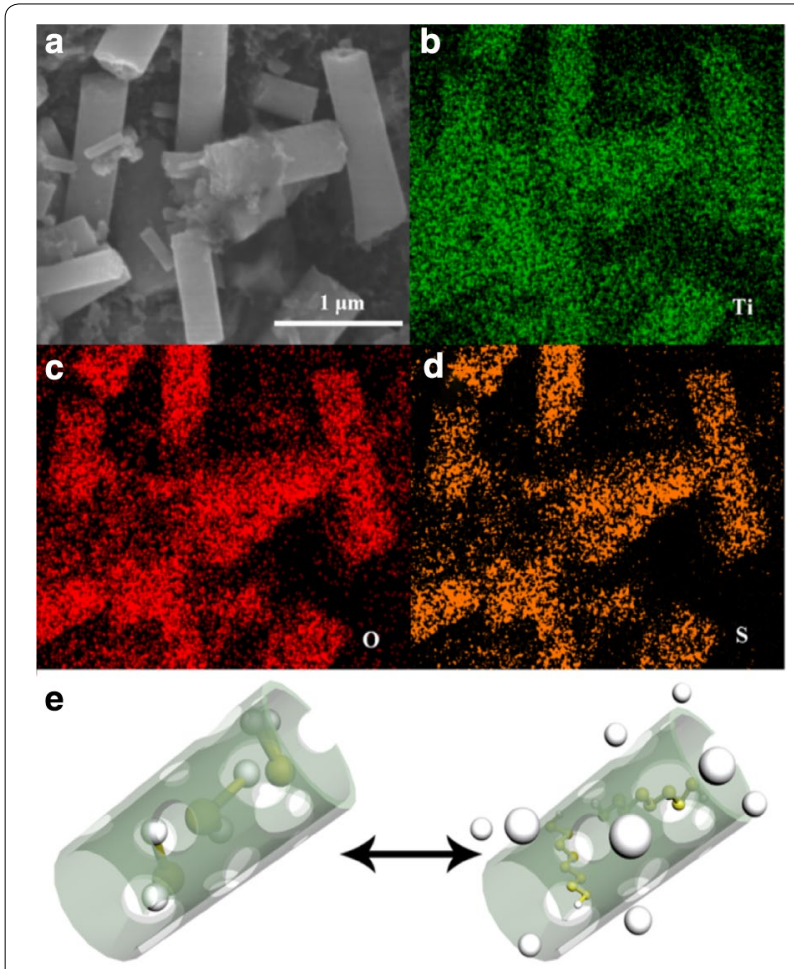

Figure 7 a SEM and $\mathbf{b}$-d elemental mapping results of $\mathrm{TiO}_{2} / \mathrm{S}$ cathode cycled 200 times at $0.1 \mathrm{C}$ rate between 1.5 and $3.0 \mathrm{~V}, \mathbf{e}$ schematic diagram of mutual transformation between $\mathrm{S}_{8}$ and $\mathrm{Li}_{2} \mathrm{~S}$ at the mesoporous $\mathrm{TiO}_{2}$ nanofibers structure
Table 1 Electrochemical performance comparison of $\mathrm{TiO}_{2}-\mathrm{S}$ with different morphologies in previously reported

\begin{tabular}{lcll}
\hline Cathode material & Cycle number & Cycling stability & Ref. No. \\
\hline $\mathrm{TiO}_{2}$ rods/S & 50 & $530 \mathrm{mAh} / \mathrm{g}(0.2 \mathrm{C})$ & {$[5]$} \\
$\mathrm{TiO}_{2}$ sphere/S & 100 & $371 \mathrm{mAh} / \mathrm{g}(1.0 \mathrm{C})$ & {$[18]$} \\
${\text { Mesoporous } \mathrm{TiO}_{2} / \mathrm{S}}$ & 100 & $676 \mathrm{mAh} / \mathrm{g}(0.5 \mathrm{C})$ & {$[8]$} \\
$\mathrm{TiO}_{2}$ sphere/S & 100 & $705 \mathrm{mAh} / \mathrm{g}(0.5 \mathrm{C})$ & {$[27]$} \\
$\mathrm{TiO}_{2}$ nanofibers $/ \mathrm{S}$ & 200 & $652 \mathrm{mAh} / \mathrm{g}(0.1 \mathrm{C})$ & This work \\
\hline
\end{tabular}

to insoluble $\mathrm{Li}_{2} \mathrm{~S}$. Because the process of elemental sulfur reacted to form lithium polysulfide and eventually to lithium sulfide, which is always carried out in $\mathrm{TiO}_{2}$ nanofibers, it could prevent the soluble lithium sulfide from being dissolved in the electrolyte, indicating the remission of the "shuttle effects". Meanwhile, the volume expansion caused by the conversion of sulfur into lithium sulfide could be alleviated, because of $\mathrm{TiO}_{2}$ nanofibers with mesoporous structure. The electrochemical performance comparison of the $\mathrm{TiO}_{2}-\mathrm{S}$ composite between the current work and previously reported in Table 1. It shows that the $\mathrm{TiO}_{2}$ nanofibers with mesoporous structure in our work improved cycle stability of cathode for Li-S battery.

Therefore, it is owing to the following reasons of $\mathrm{TiO}_{2}$ nanofiber with mesoporous structure as highly efficient sulfur host for improving cycle stability and high efficiency of battery. Firstly, $\mathrm{TiO}_{2}$ possesses the excellent catalytic dissociation ability of lithium polysulfides. And rutile phase $\mathrm{TiO}_{2}$ can in-situ adsorb the lithium polysulfides by stable chemical bonding force leading to further trapping of polysulfide anions [29]. Secondly, the interconnected fiber architecture provided fast pathways for electron/ion transfer and the mesoporous structure provide enough large surface to infuse sulfur while physically absorbing soluble lithium polysulfides and accommodating volume changes by the charge/discharge reactions.

\section{Conclusions}

$\mathrm{TiO}_{2}$ nanofibers with mesoporous structure were prepared by post thermal-treatment of electrospun. The fibers as the superior host material to load sulfur up to the $70 \mathrm{wt} \%$ for $\mathrm{Li}-\mathrm{S}$ batteries. The $\mathrm{TiO}_{2} / \mathrm{S}$ cathode demonstrated cycle stability and high efficiency. The $\mathrm{TiO}_{2} / \mathrm{S}$ cathode maintains a capacity of $652 \mathrm{mAh} / \mathrm{g}$ at $0.1 \mathrm{C}$ after 200 cycles, corresponding to a capacity retention of $92.7 \%$. The mesoporous $\mathrm{TiO}_{2}$ fibers enhance the conductivity of sulfur, promote the utilization of sulfur and provide large active sits to absorb soluble lithium polysulfides. The mesoporous $\mathrm{TiO}_{2}$ nanofibers as cathode 


\section{host material has great potential in high-performance lithium-sulfur batteries.}

\section{Authors' Contributions}

LD and ZG was in charge of the whole trial; XS wrote the manuscript; XZ and $\mathrm{JY}$ assisted with sampling and laboratory analyses. All authors read and approved the final manuscript.

\section{Authors' Information}

Xinyu Shan, born in 1996, is currently a master candidate at Key Laboratory of Automobile Materials, School of Materials Science and Engineering, Jilin University, China. She received her bachelor degree from Jilin Jianzhu University, China, in 2018. Her research interests include solar energy and energy storage materials. Zuoxing Guo, born in 1963, is currently a professor at Key Laboratory of Automobile Materials, School of Materials Science and Engineering, Jilin University, China. University, China, in 2006

Xu Zhang, born in 1996, is currently a master candidate at Advanced Institute of Materials Science \& Department of Materials Science and Engineering, Changchun University of Technology, China. She received her bachelor degree from Changchun University of Technology, China, in 2017.

Jie Yang, born in 1996, is currently a master candidate at Advanced Institute of Materials Science \& Department of Materials Science and Engineering, Changchun University of Technology, China. She received her bachelor degree from Liaocheng University, China, in 2017.

Lianfeng Duan, born in 1981, is currently a professor at Advanced Institute of Materials Science \& Department of Materials Science and Engineering, Changchun University of Technology, China, in 2018. He received his PhD degree from Jilin University, China, in 2011. His research interests include new energy materials and devices.

\section{Acknowledgements}

The authors sincerely thanks to Feifei Zhang of National University of Singapore and Junkai Wang of University of Chinese Academy of Sciences for their critical discussion and reading during manuscript preparation.

\section{Competing Interests}

The authors declare that they have no competing interests.

\section{Funding}

Supported by National Nature Science Foundation of China (Grant No. 61774022) and Education Department of Jilin Province of China (Grant No. JJKH20181030KJ).

\section{Author Details}

${ }^{1}$ Key Laboratory of Automobile Materials, School of Materials Science and Engineering, Jilin University, Changchun 130025, China. ${ }^{2}$ Advanced Institute of Materials Science \& Department of Materials Science and Engineering, Changchun University of Technology, Changchun 130012, China.

Received: 25 May 2019 Revised: 20 June 2019 Accepted: 1 July 2019 Published online: 17 July 2019

\section{References}

[1] X L He, H Hou, X Yuan, et al. Electrocatalytic activity of lithium polysulfides adsorbed into porous $\mathrm{TiO}_{2}$ coated MWCNTs hybrid structure for lithium-sulfur batteries. Scientific Reports, 2017, 7: 40679-40687.

[2] C L Wang, K Li, F F Zhang, et al. Insight of enhanced redox chemistry for porous $\mathrm{MoO}_{2}$ carbon-derived framework as polysulfide reservoir in lithiumsulfur batteries. ACS Appl. Mater. Interfaces, 2018, 10: 42286-42293.

[3] G M Liang, J XWu, XY Qin, et al. Ultrafine $\mathrm{TiO}_{2}$ decorated carbon nanofibers as multifunctional interlayer for high performance lithium-sulfur battery. ACS Appl. Mater. Interfaces, 2016, 8: 23105-23113.

[4] R P Fang, SY Zhao, S F Pei, et al. Toward more reliable lithium-sulfur batteries: An all-graphene cathode structure. ACS Nano, 2016, 10: 8676-8682.

[5] XZ Ma, B Jin, HY Wang, et al. S- $\mathrm{TiO}_{2}$ composite cathode materials for lithium/sulfur batteries. J. Electroanal. Chem., 2015, 736: 127-131.
[6] K Mi, Y Jiang, J K Feng, et al. Hierarchical carbon nanotubes with a thick microporous wall and inner channel as efficient scaffolds for lithium-sulfur batteries. Adv. Funct. Mater., 2016, 26: 1571-1579.

[7] GX Li, J H Sun, W P Hou, et al. Three-dimensional porous carbon composites containing high sulfur nanoparticle content for high-performance lithiumsulfur batteries. Nat. Commun., 2016, 7: 10601.

[8] B Ding, L Shen, G Xu, et al. Encapsulating sulfur into mesoporous $\mathrm{TiO}_{2}$ host as a high performance cathode for lithium-sulfur battery. Electrochimica Acta, 2013, 107: 78-84.

[9] F F Zhang, S P Huang, XWang, et al. Redox-targeted catalysis for vanadium redox-flow batteries. Nano Energy, 2018, 52: 292-299.

[10] K Z Cao, H Q Liu, Y Li, et al. Encapsulating sulfur in $\delta-\mathrm{MnO}_{2}$ at room temperature for Li-S battery cathode. Energy Storage Materials, 2017, 9: 78-84.

[11] H CWang, CY Fan, Y P Zeng, et al. Oxygen-deficient titanium dioxide nanosheets as more effective polysulfide reservoirs for lithium-sulfur batteries. Chem. Eur., 2017, 23: 9666-9673.

[12] X G Han, Y H Xu, XY Chen, et al. Reactivation of dissolved polysulfides in Li-S batteries based on atomic layer deposition of $\mathrm{Al}_{2} \mathrm{O}_{3}$ in nanoporous carbon cloth. Nano Energy, 2013, 2: 1197-1206.

[13] HW Zhu, Y K Jing, M Pal, et al. Mesoporous TiO_@ N-doped carbon composite nanospheres synthesized by the direct carbonization of surfactants after sol-gel process for superior lithium storage. Nanoscale, 2017, 9: 1539-1546.

[14] F F Zhang, CLWang, G Huang, et al. FeS @ C nanowires derived from organic-inorganic hybrid nanowires for high-rate and long-life lithium-ion batteries. J. Power Sources, 2016, 328: 56-64.

[15] G G Hu, CXu, Z H Sun, et al. 3D graphene-foam-reduced-graphene-oxide hybrid nested hierarchical networks for high-performance Li-S batteries. Adv. Mater., 2016, 28: 1603-1609.

[16] Y L An, Z Zhang, $\mathrm{H} F$ Fei, et al. Ultrafine $\mathrm{TiO}_{2}$ confined in porous-nitrogendoped carbon from metal-organic frameworks for high-performance lithium sulfur batteries. ACS Appl. Mater. Interfaces, 2017, 9: 12400-12407.

[17] ZW Seh, WY Li, J J Cha, et al. Sulphur- $\mathrm{TiO}_{2}$ yolk-shell nanoarchitecture with internal void space for long-cycle lithium-sulphur batteries. Nat. Commun., 2013, 4: 1331

[18] JY Li, B Ding, GY Xu, et al. Enhanced cycling performance and electrochemical reversibility of a novel sulfur-impregnated mesoporous hollow $\mathrm{TiO}_{2}$ sphere cathode for advanced Li-S batteries. Nanoscale, 2013, 5: 5743-5746.

[19] J S Cho, Y J Hong, Y C Kang. Electrochemical properties of fiber-in-tube- and filled-structured $\mathrm{TiO}_{2}$ nanofiber anode materials for lithium-ion batteries. Chem. Eur., 2015, 21: 11082-11087.

[20] D Zheng, J Xiong, P Guo, et al. Fabrication of improved dye-sensitized solar cells with anatase/rutile $\mathrm{TiO}_{2}$ nanofibers. Nanosci. Nanotechnol., 2016, 16 : 613-618.

[21] K Mondal, M A Ali, VV Agrawal, et al. Highly sensitive biofunctionalized mesoporous electrospun $\mathrm{TiO}_{2}$ nanofiber based interface for biosensing. ACS Appl. Mater. Interfaces, 2014, 6: 2516-2527.

[22] Z A Zhang, Q Li, S F Jiang, et al. Sulfur encapsulated in a $\mathrm{TiO}_{2}$-anchored hollow carbon nanofiber hybrid nanostructure for lithium-sulfur batteries. Chem. Eur., 2015, 21:1343-1349.

[23] YY Li, Q F Cai, L Wang, et al. Mesoporous $\mathrm{TiO}_{2}$ nanocrystals/ graphene as an efficient sulfur host. ACS Appl. Mater. Interfaces, 2016, 8: 23784-23792.

[24] ZZ Yang, HYWang, L Lu, et al. Hierarchical $\mathrm{TiO}_{2}$ spheres as highly efficient polysulfide host for lithium-sulfur batteries. Sci. Rep., 2016, 6: 22990-22998.

[25] J Cao, C Chen, Q Zhao, et al. A flexible nanostructured paper of a reduced graphene oxide-sulfur composite for high-performance lithium-sulfur batteries with unconventional configurations. Adv. Mater., 2016, 28: 9629-9636.

[26] J KWang, K Q Yue, XD Zhu, et al. C-S@PANI composite with a polymer spherical network structure for high performance lithium-sulfur batteries. Physical Chemistry Chemical Physics, 2016, 18: 261-266.

[27] J Li, J Q Guo, J N Deng, et al. Enhanced electrochemical performance of lithium-sulfur batteries by using mesoporous $\mathrm{TiO}_{2}$ spheres as host materials for sulfur impregnation. Materials Letters, 2017, 189: 188-191.

[28] Q Zhao, X F Hu, K Zhang, et al. Sulfur nanodots electrodeposited on Ni foam as high-performance cathode for Li-S batteries. Nano Lett., 2015, 15: 721-726.

[29] G M Zhou, Y B Zhao, CX Zu, et al. Free-standing $\mathrm{TiO}_{2}$ nanowire-embedded graphene hybrid membrane for advanced Li/dissolved polysulfide batteries. Nano Energy, 2015, 12: 240-249. 